\title{
The National Criticality Experiments Research Center at the Device Assembly Facility, Nevada National Security Site: Status and Capabilities, Summary Report
}

September 2011

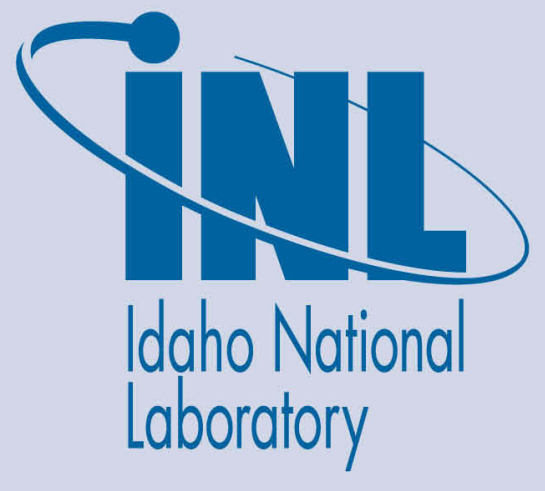

The INL is a U.S. Department of Energy National Laboratory operated by Battelle Energy Alliance 
INL/EXT-11-23428

\section{The National Criticality Experiments Research Center at the Device Assembly Facility, Nevada National Security Site: Status and Capabilities, Summary Report}

September 2011

Idaho National Laboratory
Idaho Falls, Idaho 83415

http://www.inl.gov

Prepared for the

U.S. Department of Energy

Office of National Nuclear Security Administration

Under DOE Idaho Operations Office

Contract DE-AC07-05ID14517 
WBS Task Number: High Efficiency Space Power Systems (HESPS)-TBD,

Reactor Testing and Qualification

Task Name: $\quad$ Reactor Testing and Qualification

Performing Orgs: $\quad$ INL, SNL, LANL, S. Bailey

Task Objective: $\quad$ To identify the test needs and methods to achieve certainty of design while minimizing the amount of nuclear testing required during the design and development stages of this program.

Deliverable 4: $\quad$ Issue report on status of DAF facility's ability to meet DOE-NE criticals test requirements and safety authorization basis at DAF.

Report Authors: $\quad$ S. Bragg-Sitton, J. Bess, J. Werner, INL

Task Description: An assessment describing the anticipated testing or analyses tasks necessary to provide the desired neutronic and material property data from a zero power critical test is required. The assessment should identify pertinent major testing or evaluation components of a reactor qualification campaign, and indicate the necessary validation and verification requirements of the identified tasks. The assessment will provide the basis for determining nuclear facility testing components versus non-nuclear facility testing components and the associated analytical activities of a qualification effort. The testing assessment would address issues associated data acquisition and validation, test acceptance criteria and general facility requirements.

- Develop testing and qualification strategy /approach

- $\quad$ Perform neutronic/kinetic analyses that demonstrate simplicity of reactor operation/response and quantify the affect of phenomena that cannot be addressed in a zero power critical test.

- Understand the capabilities of the DAF facility and assess impact on scope, schedule and ability to obtain the desired data.

Deliverables: Discussions with the Nevada National Security Site (NNSS) will begin to support and understand the facilities that would be available and the programmatic funding and schedule requirements of conducting desired critical tests. The report would describe the testing, analysis and tasks required to plan the initial set of critical tests. Further definition of zero power critical testing and definition of test data (values) needed for a cold critical.

- $\quad$ Issue report on prioritized high-level criticality testing needs (INL, June 2011).

- Issue report on test parameters and accuracies needed in the critical experiments for FPS (Bailey, June 2011).

- Issue letter report of reactor neutronic and kinetic calculations in an FSP model that demonstrate the effect of the uncertainty in the neutronic values to the design and stability of the reactor system (LANL, August 2011).

- $\quad$ Report on status of DAF facility's ability to meet DOE-NE criticals test requirements and safety authorization basis at DAF (September 2011). 


\title{
The National Criticality Experiments Research Center at the Device Assembly Facility, Nevada National Security Site: Status and Capabilities, Summary Report
}

\author{
Complete Report Available at Idaho National Laboratory
}

\section{Introduction}

The National Criticality Experiments Research Center (NCERC) was officially opened on August 29, 2011. Located within the Device Assembly Facility (DAF) at the Nevada National Security Site (NNSS), the NCERC has become a consolidation facility within the United States for critical configuration testing, particularly those involving highly enriched uranium (HEU). The DAF is a Department of Energy (DOE) owned facility that is operated by the National Nuclear Security Agency / Nevada Site Office (NNSA/NSO). User laboratories include the Lawrence Livermore National Laboratory (LLNL) and Los Alamos National Laboratory (LANL). Personnel bring their home lab qualifications and procedures with them to the DAF, such that non-site specific training need not be repeated to conduct work at DAF. The NNSS Management and Operating contractor is National Security Technologies, LLC (NSTec) and the NNSS Safeguards and Security contractor is Wackenhut Services. The complete report provides an overview and status of the available laboratories and test bays at NCERC, available test materials and test support configurations, and test requirements and limitations for performing sub-critical and critical tests. The current summary provides a brief summary of the facility status and the method by which experiments may be introduced to NCERC.

\section{National Criticality Experiments Research Center}

The Critical Experiments Facility (CEF) was rechristened the National Criticality Experiments Research Center (NCERC) at its official opening on August 29, 2011. Critical operations commenced at NCERC in June 2011, kicking off a series of check-out tests that will be used to validate facility operation and to quantify facility-related uncertainties in the resulting measurements. All experiments planned for the NCERC, either for sub-critical or critical testing, must be of benchmark quality for ultimate inclusion in the International Criticality Safety Benchmark Evaluation Project (ICSBEP).

Meetings were held at the NCERC on August 15 and 16, 2011 to ascertain the current status of NCERC operations and its applicability to potential fission surface power (FSP) testing needs. All experiments must be requested through the NCSP Integral Experiments Request process, as detailed in section III. However, discussions with NCERC personnel provided rough, "ballpark" estimates on potential cost of critical experiments in addition to providing information on available test facilities and test limitations. From these discussions and facility tours, we believe that the critical and sub-critical tests designed to support FSP reactor development, validation, and verification could be performed using existing test support structures at NCERC. Materials necessary for conduct of the proposed tests also appear to be available at either NCERC or INL (with planned shipment to NCERC), although detailed experiment design is required to fully ascertain what is appropriate to the FSP test series relative to what is currently available. 
Assuming all materials necessary for a given critical test are available and that no facility modifications are required to conduct a given test, NCERC personnel estimate that it would cost less than $\$ 500 \mathrm{k}$ (possibly as low as $\$ 300-400 \mathrm{k}$ ) to conduct a cold, zero power critical on one of the existing test structures and that it would take approximately six months to plan and conduct the tests. Addition of electric heating to the configuration to perform "warm" zero power critical tests could add another $\$ 100 \mathrm{k}$ for additional safety analyses, again assuming that no facility modifications are required to dissipate the heat generated by the electric heaters. Assuming that only a few $\mathrm{kW}$ are required to heat the test configuration, existing air handlers in the test cells are expected to be sufficient. Previous evaluations of the cost to conduct experiments at NCERC were significantly higher than the ballpark estimate provided. The previous estimates likely assumed introduction of stand-alone test support configurations, and may also have included costs for modifications to the NCERC that were not yet complete. Now that the NCERC is operational and test support structures are available, estimated costs reflect conduct of safety analyses and reviews for specific experiments and actual conduct of those experiments without any subsidy of the facility itself.

Conduct of a critical experiment on a new, stand-alone configuration / test support structure would cost upwards of $\$ 10,000,000$ and take 3-4 years to complete. The increase in time and cost result from requirements for a full review of the design and associated safety systems, installation of a complete, dedicated control console, and full Operational Readiness Review (ORR), as the new unit would not fall within the ORRs completed for the existing NCERC assembly devices.

\section{Nuclear Criticality Safety Program}

The mission of the Department of Energy Nuclear Criticality Safety Program (NCSP) is to "provide sustainable expert leadership, direction, and the technical infrastructure necessary to develop, maintain, and disseminate the essential technical tools, training, and data required to support safe, efficient fissionable material operations within the DOE." The vision for the NCSP is that it "will be a continually improving, adaptable, and transparent program that communicates and collaborates globally to incorporate technology, practices, and programs to be responsive to the essential technical needs of those responsible for developing, implementing, and maintaining nuclear criticality safety." Dr. Jerry McKamy of the National Nuclear Security Administration (NNSA) is the current NCSP Manager. The NCSP falls within NA-17, the NNSA Office of Facility and Infrastructure Acquisition and Operation. Additional details on the NCSP can be found at http://ncsp.1lnl.gov/ncspMain.html. NA-17 provided the funding necessary for DAF facility modifications in support of establishing the NCERC and continues to provide some annual operating budget to NCERC and to the overall NNSS.

The DOE NCSP is chartered with maintaining the technical infrastructure necessary to perform safe, efficient operations from a criticality safety perspective. Integral experiments (IE) are included as one of six technical program elements within NCSP. The NCSP mission and vision document (available at http://ncsp.llnl.gov/NCSP-MV-COMPRESSED.pdf) states:

The IE Element will provide a sustainable infrastructure and a systematic, interactive process to assess, design, perform, and document integral criticality safety-related benchmark-quality experiments to support safe, efficient fissionable material operations. 
This mission is accomplished via a Critical Subcritical Experiment Design Team (CEdT) process. All new integral experiments must be proposed and approved through the CEdT process to ensure that the requestor's nuclear data validation needs are well understood and will be met by the design and conduct of the resulting experiment. The current CEdT manager is Nichole Ellis (Ellis Nuclear Engineering LLC). To submit an unclassified integral experiment request (IER), a request form (available at the NCSP website) must be submitted. Classified experiments shall be requested by alternate method and should be discussed with the CEdT Manager or the NCSP Manager or Deputy.

Experiment scheduling is managed via a five year strategic plan, with reassessment of the established experiment priority being conducted on an annual basis to take into account newly submitted requests. Experiments are prioritized based on an established priority classification, detailed below. The priority of a given project is set by the highest priority classification identified.

\section{IER prioritization:}

1. NA-11/-12 (NNSA Research Development and Simulation; Military Applications and Stockpile Operations)

2. NA-40 (NNSA Emergency Operations)

3. NA-20 (NNSA Defense Nuclear Non-proliferation)

4. NA-30 (NNSA Office of Naval Reactors)

5. Programmatic Criticality Safety Needs

6. EM (DOE Environment Management)

7. NE (DOE Nuclear Energy)

8. Long Standing Criticality Physics Discrepancies

Although funding is not required to accompany an experiment request, the availability of funding from the requesting project will increase the prioritization of the request. Funding to conduct experiments may also be provided by the NCSP if there is a general need for the requested data within the national criticality safety community; requests that have a tie to Homeland Security may have a higher prioritization and potential for NCSP funding. On average, NNSA funds approximately two experiments per year to be conducted at one of the partner critical experiments facilities. Possible test facilities include the NCERC and Sandia National Laboratories in the United States, Valduc in France, and VNIITF in Russia. The CEdT process will identify the facility is most appropriate for a given experiment request. NCERC is designated as a center of excellence for criticality testing of metal systems.

The NCSP has previously offered a 4-day criticality safety training course. A new two-week hands-on training course has been established, with the pilot program held in late August 2011. It is expected that four courses will be held in FY2012, with a potential for eight courses per year in future years. There will be no registration fee associated with the course, but seats will be prioritized by need, role of the student in planned tests, etc. The course will include one week of "book learning" at LANL covering the following topics:

- DOE perspective on criticality safety regulations, standards and guides

- Major emphasis on practical student exercises to developing criticality safety evaluations with:

○ TA-55/PF-4 tours and examples 
○ DOE-STD-3007-2007 compliance

- Proper utilization of NDA measurement data

- Role of Hazards Analysis

- Human Factors

○ Equipment Reliability

The second week of the course will take two potential paths depending on the clearance level of the student. Q- and L-cleared personnel will participate in a second week of training at the National Nuclear Security Site, where there will be major emphasis on "hands-on" subcritical and "remote" critical experiments. The alternate second week of training for uncleared personnel will be held at Sandia National Laboratories and the University of New Mexico. Registration, syllabus, prerequisites, logistics and contact information should be available at the NCSP website in October 2011.

The Integral Experiments Request (IER) form is relatively simple, but sufficient detail must be included to ensure the that the CEdT can accurately review the request, determine if any of the requested data may be available from previous experiments, and establish the proper prioritization of the request. Prior to submitting an IER, the requestor should conduct a thorough review of available integral data (ICSBEP, Published, Unpublished, etc.) and identify the presumed gap in the data. The CEdT review process will conduct an additional search to determine if any resources have been missed and if the required data does in fact exist. The suggested experiment concept should clearly define the data needs and necessary measurement sensitivity. Measurements of interest might include the effective multiplication coefficient, reaction rates, neutron spectrum, reactivity worths of various components, kinetic parameters, reactivity feedback coefficients, etc. The CEdT process goes through five Critical/Subcritical Experiment Decision (CED) steps, as detailed in the Critical \& Subcritical Experiment Design Team Process Manual, each of which must be approved by the NCSP Manager. These steps include:

CED-0 Justification of Integral Experiment Need

CED-1 Integral Experiment Conceptual Design

CED-2 Integral Experiment Final Design

CED-3 Approval to Conduct the Integral Experiment

CED-4 Publication of Data

Approved integral experiments can be viewed at the IER link on the NCSP web site if the user accesses the site from a DOE / DOE laboratory domain. If an approved experiment request could potentially satisfy the data need identified in a new request, additional measurements may be added to the approved request to fulfill the additional data need. The list of approved experiments should be reviewed prior to submission of a new IER. 